\title{
Editorial: Confessions of a New Editor-in-Chief
}

It is a humbling but exciting experience to take over as editor-in-chief of the Canadian Journal on Aging. As I write this editorial I am coming up on my threemonth anniversary. It is customary to thank people when one comes to the end of tenure in a position such as this, but I want to start by thanking a number of people who have made the start of my term possible.

First, I want to thank Carolyn Rosenthal, the outgoing editor-in-chief, and Anne Marie Corrigan, our managing editor at the University of Toronto Press, for their cooperation and patience in making the transition so smooth. There is much more in a transition than just shifting files from one office to another. I will not bore you with the details, but suffice it to say, there have been occasions when Carolyn or Anne Marie provided wisdom where I had none. I also want to thank Carole Cohen, Daniel Lai, Thomas Hadjistavropoulos, Norm O'Rourke, Ingrid Connidis (section editors), and Lucie Richard (book review editor), who have been highly supportive in offering me frank advice about the manuscripts I have circulated and some of the ideas I have for the journal. Third, I want to thank the authors of the manuscripts I have processed so far. I am learning all over again about the importance of following style guides. I know I have asked some authors to make stylistic changes that should not have been made, and I know I will probably continue to make requests that authors might question. For the former, I apologize, and for the latter, please feel free to get in touch with me.

As we begin 2005, the journal has never been so healthy. Borrowing from Carolyn's report to the annual general meeting in Victoria, I want to remind readers that in 2004 the journal was finally accepted for indexing with Medline/Index Medicus. This has been a long-term goal of many people who have worked on the journal. We owe all of them a special debt of gratitude, but Carolyn and Anne Marie, in particular, deserve accolades for this achievement. Quoting from Carolyn's report, "[T] he total number of submissions increased from 60 in 2002 to 68 in 2003 and seems set for a larger increase this year. As of Oct. 24, 2003, there had been 53 manuscripts submitted. At October 6, 2004, a total of 62 manuscripts had been submitted. The total for 2004 is likely to reach 75-80." Carolyn's goal was to see 100 manuscripts submitted per year, and I hope we will achieve this in 2005. It would mean that each issue of the journal would likely have eight to ten articles.

We continue to receive financial support from the Canadian Institutes of Health Research Institute on Aging, and the Social Sciences and Humanities Research Council of Canada (SSHRC), which is much appreciated. As 2005 begins, we now know that we have a new three-year publication grant from SSHRC, and we look forward to ongoing support from the Institute on Aging.

As a geographer, social scientist, and gerontologist, I have learned a lot from reading the Canadian Journal of Aging. Now I am learning a lot more as your editor-in-chief. In all of the journals in which I have been involved as an editor, I have always believed that the journals belong to the authors and readers, and that the editor is there to work for you, not the other way around. In future editorials, I want to begin a dialogue on how we can improve the journal over the course of my term as editorin-chief. I am always interested in the views of authors and readers and how I can do a better job for you. Feel free to contact me any time at rosenber@post.queensu.ca. 